\title{
Acute myelopathy in association with heroin addiction
}

\author{
J J ELL, D UTTLEY AND J R SILVER \\ From the Department of Neurology, The Middlesex Hospital, London and the National Spinal Injuries \\ Centre, Stoke Mandeville Hospital, Aylesbury
}

SUMMARY The occurrence of spinal cord lesions in association with self-administration of heroin is a recognised entity in the United States of America which has not up to now been reported in British literature. Three cases are described, the literature reviewed and possible aetiological factors discussed.

\section{Case reports}

Case 1 A 19-year-old white caucasian male was admitted to Ashford General Hospital in October 1971. He had become addicted to heroin one year prior to this illness and to other drugs at the age of 16 years. Three days prior to admission he had intravenously administered the contents of eight "bags" of heroin to himself. He evidently had been lying unconscious with his neck hyperextended for the next 24 hours. On regaining consciousness he was unable to move his legs. Admission was subsequently delayed owing to the patient's difficult social circumstances. On admission he was hypotensive, with blood pressure $80 / 40 \mathrm{mmHg}$. He was tender over the spine of C7. There was a flaccid quadriplegia with a sensory level at $\mathrm{C} 7$. He had urinary retention. Examination of the CSF showed a protein of $0.28 \mathrm{~g} / \mathrm{l}$, one white cell and two red blood cells per $\mathrm{mm}^{3}$. He was transferred to the Atkinson Morley's Hospital the following day. A myelogram showed localised swelling at C4-5. The patient was treated with dexamethasone $2 \mathrm{mg}$ four times a day. Seventeen days later he was transferred to the National Spinal Injuries Centre, Stoke Mandeville where, in addition to the above examination, a unilateral Horner's syndrome was noted. Two months later there had been a moderate recovery. He was able to walk with the aid of both a caliper and a plaster cylinder. He was continent of both urine and faeces, initiating micturition by suprapubic tapping. On formal examination there was a partial Brown-Séquard syndrome with a level on the left at C7. He was discharged at the beginning of 1973 and has been seen regularly until 1980 .

Address for reprint requests: Dr JR Silver, National Spinal Injuries Centre, Stoke Mandeville Hospital, Mandeville Road, Aylesbury, Bucks, HP21 8AL, UK.

Accepted 10 March 1981
He has taken no further heroin and has continued to show improvement of motor power in his lower limbs.

Case 2 A 39-year-old white caucasian female was admitted to the Middlesex Hospital in July 1979. She had poliomyelitis at the age of 11 years, making a good recovery with residual wasting and weakness of the right deltoid and right anterior tibial compartment muscles. At the age of 17 years she had become addicted to heroin. For many months prior to admission she had taken $30 \mathrm{mg}$ of pure heroin each day. For two weeks before admission she had, in addition, administered intravenously impure "Chinese" heroin. On the evening of admission she had taken her usual dose of pure heroin in addition to Tuinal $200 \mathrm{mg}$. She had been walking normally prior to this. On admission she was hypotensive and pyrexial, blood pressure ranging from $90 / 60$ to $80 / 40 \mathrm{mmHg}$, temperature $30 \cdot 5^{\circ} \mathrm{C}$ to $40^{\circ} \mathrm{C}$. There was an abscess at an injection site on the left thigh. She was deeply comatose and requiring artificial respiration. Two days later she had sufficiently recovered to complain of inability to move her legs. On examination she was mildly tender over D7 and D8 vertebrae. There was total flaccid paraplegia with a sensory level at D8. A myelogram that day was normal. CSF examination showed a protein of $0.2 \mathrm{~g} / \mathrm{l}$, glucose $3.0 \mathrm{~m} \mathrm{~mol} / 1$, Lange non-reactive, one red blood cell and one white blood cell per $\mathrm{mm}^{3}$. Three months later there was some return of posterior column function bilaterally; she was aware of movement in both small and large joints and was able to localise a firm cutaneous stimulus. She remained paraplegic and requiring urinary catheterisation. She was discharged in December 1979 and had out-patient physiotherapy at the Wolfson Centre, She has taken no further heroin and when examined in January 1981, there was found a considerable improvement in power in the right lower limb, in the psoas, flexors and extensors of the toes and foot. She was still spastic with a sensory level at D7. 
Case 3 A 17-year-old white caucasian female was admitted to the Middlesex Hospital in September 1979 following an attempted suicide by over-dosage of drugs. She had become addicted to phenobarbitone at the age of 11 years, adding methadone hydrochloride to this one year later. She had been administering "Chinese" heroin to herself for at least one week prior to the overdose and subsequently reported that she had been aware of weakness in the lower limbs during that period. On the evening of admission she injected intravenously an unknown quantity of quinalbarbitone sodium and amylobarbitone sodium and approximately $20 \mathrm{mg}$ of methadone hydrochloride. On examination she was unconscious and unresponsive. Her temperature was $32.5^{\circ} \mathrm{C}$ and blood pressure $80 / 50 \mathrm{mmHg}$. She remained hypotensive for 24 hours. Forty-eight hours later she was conscious and breathing spontaneously. During the following days she reported difficulty with micturition and movement of the lower limbs. On examination 12 days after the overdose there was severe weakness of the right lower limb with no voluntary movement in the left lower limb. The knee and ankle jerks were brisker on the left; the right plantar response extensor, the left equivocal. Joint position and vibration sensation were severely impaired on the right to the level of D11 and markedly impaired on the left to the level of D8. She thus showed signs of a partial BrownSéquard Syndrome at the level of D8 on the left. A myelogram was normal. CSF examination showed a protein of $0.30 \mathrm{~g} / \mathrm{l}$, one white blood cell and one red blood cell per $\mathrm{mm}^{3}$. In the following months there was marked improvement so that she was able to walk unassisted. Accurate assessment, however, was not possible because of the development of marked psychological overlay, the patient adopting the role of a wheelchair-bound invalid.

\section{Discussion}

The general medical complications of heroin addiction are numerous and well documented. ${ }^{12}$ The neurological complications are varied. ${ }^{34}$ They include lumbar and brachial plexitis, ${ }^{56}$ rhabdomyolysis, ${ }^{8}$ polyradiculopathy and polyneuropathy, ${ }^{910}$ brain abscess and mycotic aneurysm, ${ }^{11}$ spinal cord compression, ${ }^{12}$ stroke, ${ }^{13}$ tetanus, ${ }^{14}$ crush syndromes, ${ }^{7}$ and also injection neuropathy and convulsions. Since the original description, myelopathy associated with heroin addiction ${ }^{16}$ has been elucidated. Possible causative factors postulated have included hypotension, toxic or hypersensitivity reactions to contaminants or to heroin itself, vasculitis, embolism of particulate adulterants and hyper-extension injury. Neither the clinical pictures nor pathological reports conform to any particular pattern. However, it is known that the prognosis for recovery, though variable as these cases demonstrate, is generally poor. It is interesting that Richter's cases were all in blacks whereas the three patients described here were white caucasians. It is difficult to attribute much significance to the slightly different clinical features on a racial basis since it may well be that the heroin used by poor blacks in America may be of different origin and have different contaminants from that used in the United Kingdom.

The Middlesex Hospital treated 850 individual drug abusers in 1979. The patients mostly obtained their drugs from "pushers" operating at or around the Piccadilly Underground Station. Heroin is bought by the packet (costing about $£ 5$ ); quinalbarbitone with amylobarbitone is bought by the capsule at about $£ 1$ per $200 \mathrm{mg}$, mixed with water (usually from a public lavatory) and injected. The heroin is "cut" with various adulterants which vary from district to district. "Chinese" heroin often contains caffeine; that from Iran is adulterated often with strychnine. Lactose, mannitol, and quinine are well established adulterants, the last of these occasionally causing blindness. ${ }^{17}$ Our patients told of talcum powder, starch, curry powder, "Vim" and "Ajax" also being used, the last being said to cause "a worse headache on waking than usual". The amount of heroin in each packet can vary from $5 \mathrm{mg}$ to $30 \mathrm{mg}$. There do not seem to be any specific diagnostic features in the pathogenesis of transverse myelopathy from an overdosage of heroin. All three patients had a significant period of hypotension. The features could be attributed to a vascular lesion of the spinal cord, secondary to a period of hypotension. Unlike Richter's original cases, the spinal cord lesions had not occurred on recurrence of heroin abuse after a period of abstinence. The first case may possibly have developed cervical myelopathy secondary to prolonged hyperextension of the neck. However, such lesions are usually the result of more violent injuries and the cervical spine $x$-rays showed no evidence of narrowing of the cervical canal or cervical spondylosis to make the patient predisposed to such a lesion. The third case reported weakness of the legs several weeks prior to the period of her maximum neurological deficit. This is suggestive of an underlying myelitic or vasculitic process and resembles Judice's case. ${ }^{18}$ The second and third cases both administered Tuinal intravenously prior to admission.

We have seen another patient who took an overdosage of barbiturates who fell asleep in a car with the head in the hyperextended position and also developed a transverse cord lesion. In view of the common incidence of barbiturate overdosage in comparison with that to heroin and the great rarity of this neurological complication it is doubtful that Tuinal contributed primarily to the development of acute myelopathy. The histories in particular of cases 2 and 3 and their close temporal proximity of presentation suggest that their development of acute myelopathy was due to an adulterant in "Chinese" 
heroin, possibly from the same shipment. If this is so then further cases may well occur and be identified as such.

We thank Dr B Laurence and Professor SJG Semple for their kind permission to report cases 2 and 3 respectively.

\section{References}

1 Louria DB, Hemsle T, Rose J. The major medical complications of heroin addiction. Ann Int Med 1967; 67:1-22.

2 Sapira JD. The narcotic addict as a medical patient. Am J Med 1968; 45:555-88.

3 Richter RW, Pearson J, Brunn B, Challenor YB, Brust JCM, Baden MM. Neurological complications of addiction to heroin. Bull NY Acad Med 1973; 49:3-21.

4 Richter RW, Pearson J. Heroin addiction related to neurological disorders. In Richter RW, ed. Medical Aspects of Drug Abuse 1975; 320-327. Hagerstown, Harper and Row.

5 Challenor YB, Richter RW, Pearson J. Neuromuscular complications of heroin addiction. Ann Intern Med 1971; 74:838.

6 Greenwood RJ. Lumbar plexitis and rhabdomyolysis following abuse of heroin. Postgrad Med J 1974; 50:772-3.

7 Richter RW, Challenor YB, Pearson J, Kagen LJ, Hamilton LL, Ramsey WK. Acute myoglobinuria associated with heroin addiction. JAMA 1971; 216:1172-6.

8 Schwartzfarb L, Singh G, Marcus D. Heroinassociated rhabdomyolysis with cardiac involvement. Arch Intern Med 1977; 137:1255-7.

9 Smith WR, Wilson AF. Guillain-Barre syndrome in heroin addiction. $J A M A$ 1975; 231 :1367-8.

10 Loizou LA, Boddie HG. Polyradiculoneuropathy associated with heroin abuse. $J$ Neurol Neurosurg Psychiatry 1978; 41:855-7.

11 Amine AR. Neurosurgical complications of heroin addiction: Brain abscess and myotic aneurysm. Surg Neurol 1977; 7:385-6.

12 Jabbari B, Pierce JF. Spinal cord compression due to pseudomonas in a heroin addict. Case Report. Neurology (Minneap) 1977; 27:1034-7.

13 Brust JCM, Richter RW. Stroke associated with addiction to heroin. $J$ Neurol Neurosurg Psychiatry 1976; 39:194-9.

14 Berger SA. Tetanus despite pre-existing tetanus antibody. JAMA 1978; 240:769-70.

15 Penn AS, Rowland LP, Fraser DW. Drugs, coma and myoglobinuria. Arch Neurol 1972; 26:336-43.

16 Richter RW, Rosenberg RN. Transverse myelitis associated with heroin addiction. JAMA 1968; 706:1255-7.

17 Brust JCM, Richter RW. Quinine ambylopia related to heroin addiction. Ann Intern Med 1971; 74:84-6.

18 Judice DL, LeBlanc, HL, McGarry PA. Spinal Cord vasculitis presenting as a spinal tumour in a heroin addict. $J$ Neurosurg $1978 ; 48: 131-4$. 